Received: 18 July 2017

Accepted: 20 October 2017

Published online: 06 November 2017
NTIFIC REP

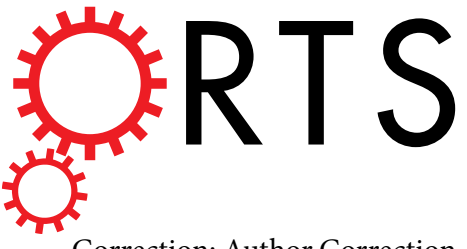

Correction: Author Correction

\title{
OPEN A role for small secreted proteins (SSPs) in a saprophytic fungal lifestyle: Ligninolytic enzyme regulation in Pleurotus ostreatus
}

\author{
Daria Feldman ${ }^{1}$, David J. Kowbel ${ }^{2}$, N. Louise Glass ${ }^{2}$, Oded Yarden ${ }^{1}$ \& Yitzhak Hadar ${ }^{1}$
}

Small secreted proteins (SSPs), along with lignocellulose degrading enzymes, are integral components of the secretome of Pleurotus ostreatus, a white rot fungus. In this study, we identified 3 genes (ssp1, 2 and 3 ) encoding proteins that are annotated as SSPs and that exhibited of $\sim 4,500$ - fold expression, $24 \mathrm{hr}$ following exposure to the toxic compound 5-hydroxymethylfurfural (HMF). Homologues to genes encoding these SSPs are present in the genomes of other basidiomycete fungi, however the role of SSPs is not yet understood. SSPs, aryl-alcohol oxidases (AAO) and the intracellular aryl-alcohol dehydrogenases (AAD) were also produced after exposure to other aryl-alcohols, known substrates and inducers of AAOs, and during idiophase (after the onset of secondary metabolism). A knockdown strain of ssp1 exhibited reduced production of AAO-and AAD-encoding genes after HMF exposure. Conversely, a strain overexpressing ssp1 exhibited elevated expression of genes encoding AAOs and $A D D$, resulting in a 3 -fold increase in enzymatic activity of $A A O$ s, as well as increased expression and protein abundance of versatile peroxidase 1 , which directly degrades lignin. We propose that in addition to symbionts and pathogens, SSPs also have roles in saprophytes and function in P. ostreatus as components of the ligninolytic system.

Fungi secrete proteins that participate in polymeric organic matter degradation, such as proteases, lipases and carbohydrate-active enzymes ${ }^{1}$ or facilitate interactions through surface proteins such as hydrophobins, or small-secreted proteins (SSPs) ${ }^{2,3}$. In fungi, SSPs are characteristically shorter than 300 amino acids and have a secretion signal peptide ${ }^{3}$. SSPs are mostly present in fungi that interact with living plants and some of these SSPs have been referred to as 'effectors', which are key factors in plant infection that are involved in modulating plant response to infection ${ }^{1}$. In saprophytic fungi, SSPa have been suggested to be involved in degradative capabilities, as in the case of the Trichoderma reesei swollenin protein, which mediates depolymerization of cellulose ${ }^{4}$. SSPs are mostly encoded by orphan genes with no known PFAM (protein families database) domains. Only a few SSPs have been functionally characterized ${ }^{2,3}$.

In a previous study, we explored the ability of Pleurotus ostreatus, a white-rot fungus, an efficient degrader of lignocellulose and a variety of aromatic compounds, to metabolize 5 -hydroxymethylfurfural (HMF) ${ }^{5}$. This toxic compound is generated during the pretreatment of cellulosic biomass for $2^{\text {nd }}$ generation biofuel production, and is considered as a key technical challenge in the process ${ }^{6-9}$. We demonstrated that $P$. ostreatus bioconverts HMF via enzymes involved in lignin degradation, including the extracellular $\mathrm{H}_{2} \mathrm{O}_{2}$-generating aryl-alcohol oxidases $(\mathrm{AAO})$ and the intracellular aryl-alcohol dehydrogenases $(\mathrm{AAD})^{10,11}$. Other important lignin-modifying enzymes are the extracellular metal-containing oxidoreductases, which include enzymes that utilize hydrogen peroxide, manganese peroxidases [MnPs, as well as versatile peroxidases (VPs) ${ }^{12-14}$, lignin peroxidase, laccase and dye peroxidase $^{10}$.

In the current study, we identified genes encoding a family of $P$. ostreatus SSPs, in whose expression was upregulated in response to exposure to HMF or other aryl alcohols. The expression of these SSP coding genes was also increased, even in the absence of the inducer, at the onset of idiophase (the growth phase in which secondary

${ }^{1}$ The R.H. Smith Faculty Agriculture, Food and Environment, The Hebrew University of Jerusalem, Department of Plant Pathology and Microbiology, Rehovot, 76100, Israel. 'University of California at Berkeley UC Berkeley, Department of Plant and Microbial Biology, 111 Koshland Hall, Berkeley, California, 94720, USA. Correspondence and requests for materials should be addressed toY.H. (email: yitzhak.hadar@mail.huji.ac.il) 
metabolism occurs). Genetic manipulation of SSP-coding genes, by introduction of either knockdown or overexpression cassettes into P. ostreatus resulted in effects on AAOs, AAD and VP, at the transcriptional, translational and enzyme activity levels. We suggest that the SSPs function to facilitate induction of the ligninolytic system, although the nature of the regulatory pathway associated with induction is yet unclear. Most analyses of SSP function have focused on their involvement in pathogenic or symbiotic lifestyles of various fungi. We now demonstrate that SSPs have a function during the onset of activity of the ligninolytic system in a fungus whose lifestyle is completely saprophytic.

\section{Results}

Small Secreted Protein (SSP) expression is induced after exposure to HMF. Previously, we reported on the involvement of the lignin-modifying enzymes AAO and AAD in the transcriptional response to HMF, as well as in its degradation ${ }^{5}$. To determine if other genes associated with the ligninolytic process are potentially affected by the presence of HMF, we performed RNA-seq analysis on 5-day-old cultures exposed to HMF for 24 hrs. The expression of 15 out of 39 genes encoding AAOs, and 6 genes out of 8 encoding AADs was significantly increased. Among the 9 members of the MnP family, which also consists of VP enzymes ${ }^{12-14}$, only the expression of $m n p 1$ was significantly increased ( 2 -fold; Supplementary Table $S 1)$. In addition, expression of two laccase encoding genes was affected: PoLACC6 (POXA1B) and PoLACC3, which were both upregulated ( 3.8 and 2.2 fold, respectively) (Table S1). A summary of all genes whose expression was affected by the addition of HMF can be found in Table 22 .

In addition to the expected and previously described changes in gene expression ${ }^{5}$, a marked increase in the expression of 3 genes that encode for small secreted proteins was evident. The 3 genes: 65712, 46202 and 91630 were upregulated between 250-900-fold, relative to the control. The genes share a high degree of similarity and are predicted to encode small $(\sim 18 \mathrm{kDa})$ proteins. Bioinformatic analyses revealed that the identifiable conserved motif (present in the three proteins) was a signal peptide. Similar proteins, found in other fungi, have been designated SSPs (Small $\underline{S}$ ecreted Proteins) ${ }^{2}$. Thus, we designated the mentioned $P$. ostreatus proteins ssp1, 2 and 3 , respectively. The expression level of three additional genes in the $P$. ostreatus genome that belong to the same family $(90499,44261$ and 100993, designated ssp4, 5, and 6) was not affected.

Homologues of the P. ostreatus SSP family are present in the genomes of other fungi (Table S3) ${ }^{15,16}$, mostly in basidiomycete species in the Agaricomycotina, such as Pleurotus eryngii and Coprinopsis cinerea, where their function is also unknown. Ssp1 is highly similar (E value of 4.39E-023) to the Laccaria bicolor MISSP24 (protein id 293250). MISSP24 was annotated as a small putative secreted protein, which is up-regulated during ectomycorrhizal growth of L. bicolor in Populus and Douglas fir and in fruiting bodies of the fungus (http://genome. jgi-psf.org/Lacbi2/Lacbi2.home.html). Though P. ostreatus is not an ectomycorrhizal fungus, it may suggest that SSPs play a role in $P$. ostreatus' natural habitat as well and suggest a conserved function with other SSPs-containing fungi ${ }^{1,2}$.

To verify the results obtained by the RNA Seq procedure and further monitor the induction of SSP over time after exposure to HMF, we constructed specific primers for RT- PCR. The primers were constructed on the basis of the $s s p 1$ gene, but due to the high similarity of $s s p 1$ to the other $s s p$ genes in the family we regarded the amplicon obtained, which contained a mixture of at least three gene products, as the collective expression of $\operatorname{ssp} 1,2$ and 3. When the cultures were not exposed to HMF, the expression of all ssps was very low, $5^{*} 10^{-04}$ relative to $\beta$-tubulin in 5-7-day-old cultures. A 4 -fold increase in the expression of ssp genes occurred within 30 minutes after addition of $30 \mathrm{mM} \mathrm{HMF}$, followed by a $\sim 650$-fold and $\sim 5550$-fold increase after 8 and 24 hours, respectively. After 48 hours of exposure to the furan, the expression of the ssp genes was reduced to $\sim 950$-fold, relative to the control ( 0.11 relative to $\beta$-tubulin) (Fig. 1$)$. The time points corresponded to the time course of biotransformation of HMF by $P$. ostreatus: the extracellular concentration was reduced by $\sim 10 \%$ after 8 hours, $50 \%$ reduction by 24 hours, and complete biotransformation occurred after 48 hours $^{5}$. These results suggested that the level of the induction of ssp genes correlated with the amount of HMF in the medium, as well as with its degradation kinetics by the fungus.

In order to verify that the increase in RNA levels leads to accumulation of the predicted SSP proteins, the fungal secretomes were resolved by SDS-PAGE. We observed a high level of $\sim 15 \mathrm{kDa}$ proteins (corresponding to the expected size of the $s s p$ gene products), which were present only in medium from cultures that had been exposed to HMF for 24 or 48 hrs (Fig. 1). To determine the identity of the SSPs in the secretome of P. ostreatus, we analyzed the relevant PAGE bands by mass spectrometry (MS) and identified the corresponding proteins, Ssp1 and Ssp2, at a very high abundance. Though the expression of $s s p$ genes was highly induced $8 \mathrm{hr}$ after exposure to HMF (Fig. 1), we only detected the presence of the corresponding proteins at later time points. A possible explanation for this may be the time required between the transcription, translation/secretion and accumulation of these SSP proteins in the media.

SSPs, AAOs and AAD are induced by exposure to aryl-alcohols. The AAO and AAD gene family members are involved in HMF biotransformation, and involved in the transcriptional and translational response to the chemical in P. ostreatus ${ }^{5}$. As the expression of these two gene families in response to HMF coincides with that of the SSPs, we hypothesized that the induction and accumulation of SSPs might be linked with HMF metabolism. To explore this possibility, we chose several known substrates or inducers of AAOs, and determined the transcriptional and translational response of AAOs following the addition of $30 \mathrm{mM}$ of each chemical. We analyzed the fungal response to 3 aryl alcohols: veratryl alcohol (VA), 4-methoxybenzyl alcohol (MBA) and benzyl alcohol (BA) (Fig. 2). All the chemicals induced ssp gene expression, as measured $24 \mathrm{hr}$ after their addition to the media. The most significant induction occurred after the addition of HMF ( 3670 -fold), followed by BA and MBA ( 1425 and $\sim 1865$ fold, respectively), and only $\sim 7$-fold in VA-amended medium (Fig. 2$)$. The transcriptional induction of the ssp1-3 was coupled with induction of genes encoding AAO1-3 and AAD1, by exposure 
A
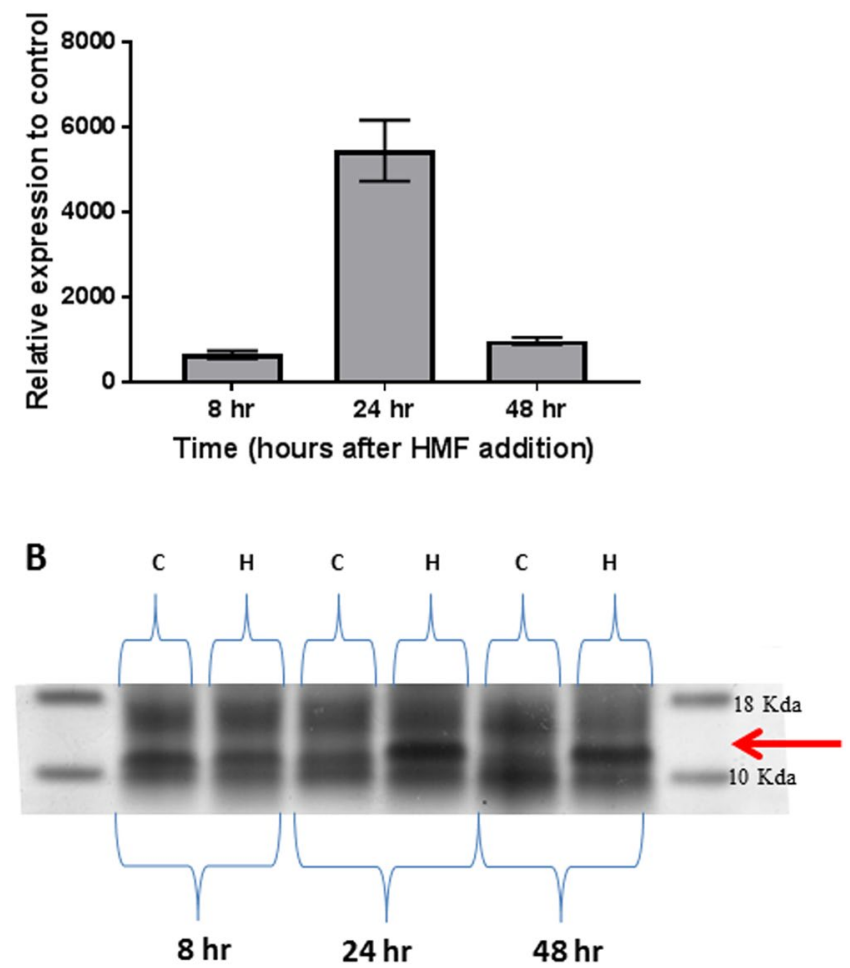

Figure 1. Elevated gene expression and protein abundance of Ssp1-3 in P. ostreatus following HMF exposure. The expression of ssps relative to control (A) and secreted protein abundance of SSPs, relative to total secreted proteins (B), were analyzed 8,24 and $48 \mathrm{~h}$ after addition of $30 \mathrm{mM}$ of HMF to the media. The identification is based on MS. Arrow points to SSPs.

to all chemicals, albeit at different levels (Fig. 2). AAO activity, as measured calorimetrically, was induced by the presence of VA and BA, but 4-fold less than by HMF (after the addition of MBA, AAO activity could not be measured due to technical limitation of the assay) (Fig. 2). Additional compounds, tested as controls, such as other furans (furfural and furfuryl alcohol) and a known inducer of laccase (guaiacol) did not trigger the same reaction in gene expression.

Elevated expression of genes encoding SSPs was coupled with elevated expression of genes encoding AAOs and AAD when exposed to HMF, VA, BA or MBA. These chemicals are toxic to P. ostreatus at the concentrations used, and significantly reduced the growth rate of the fungus. All the molecules tested share a common aryl alcohol moiety, or in the case of HMF (Fig. 2), a C-OH bond to a ring, which we suggest is probably mandatory, but not the only functional group, required for triggering the response.

SSPs gene expression is induced during the idiophase. The similar reaction of the ssps, aaos and aad genes to the same molecules, which can also all serve as a substrate for AAO, led us to hypothesize that the 3 gene families might be expressed under the same conditions. We measured AAO activity at different growth stages for over 24 days of growth, to be used as a potential marker to identify the culture conditions under which these genes are expressed. During the fungal growth phase (the first 10-11 days following inoculation), AAO activity was not detected. 12-13 days following inoculation, at the beginning of the idiophase, as the fungus enters a stage where secondary metabolism occurs ${ }^{17}$, there was a significant increase in AAO activity. We focused on 6, 13 and 18-day-old cultures, representing cultures lacking detectable AAO activity, an early AAO induction phase and a high activity phase, respectively (Fig. 3).

At day 13, the culture showed the highest level of ssp transcript abundance (1.33 relative to $\beta$-tubulin), which decreased after 18 days $(0.0057$ relative to $\beta$-tubulin) (Fig. 4). At the protein level, high amounts of SSPs were detected on both days 13 and 18, and were accompanied by high levels of AAOs and AAD protein abundance in the secreted and cellular fractions, respectively (Fig. 5).

Knockdown of SSP results in reduced expression of AAO and AAD after HMF exposure. In an attempt to reveal the function of SSPs in P. ostreatus, we took a reverse genetics approach to determine if silencing the corresponding genes would result in altered sensitivity to HMF. Specifically, we generated an RNAi construct designed to interfere with the expression of the entire ssp gene family. The plasmid was constructed by incorporating a highly conserved 160-bp ssp gene fragment (based on the sequence of ssp1) arranged in a forward and a reverse orientation, where the ssp 1 fragment flanks a 213 bp loop. This construct was inserted into pTMS1 [which 

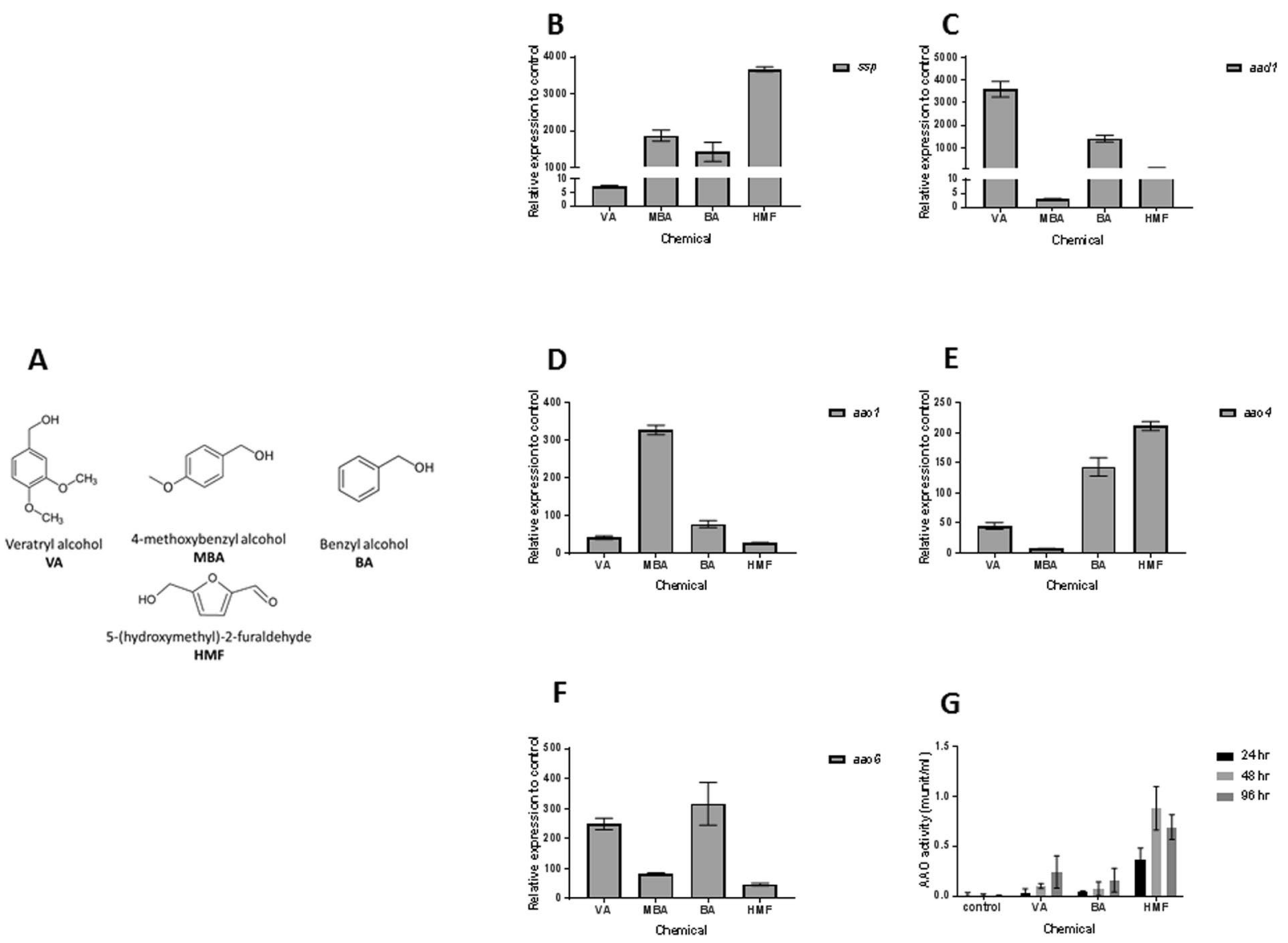

Figure 2. Elevated gene expression of ssps, aaos and aad and increased in vitro AAO activity following exposure to aryl-alcohols and HMF. (A) Chemical structure of Veratryl alcohol (VA), 4-methoxybenzyl alcohol (MBA), benzyl alcohol (BA) and HMF (B) $30 \mathrm{mM}$ of VA, 4- MBA, BA or HMF were added to P. ostreatus media. Relative gene expression to control of ssps (B), aad 1 (C) and aao1,4, and $6(\mathbf{D}-\mathbf{F})$ was analyzed following 24 hours exposure to the chemicals. In vitro AAO activity in free cell extracts $(\mathbf{G})$ was measured 24, 48 and 96 hours following the chemicals addition.

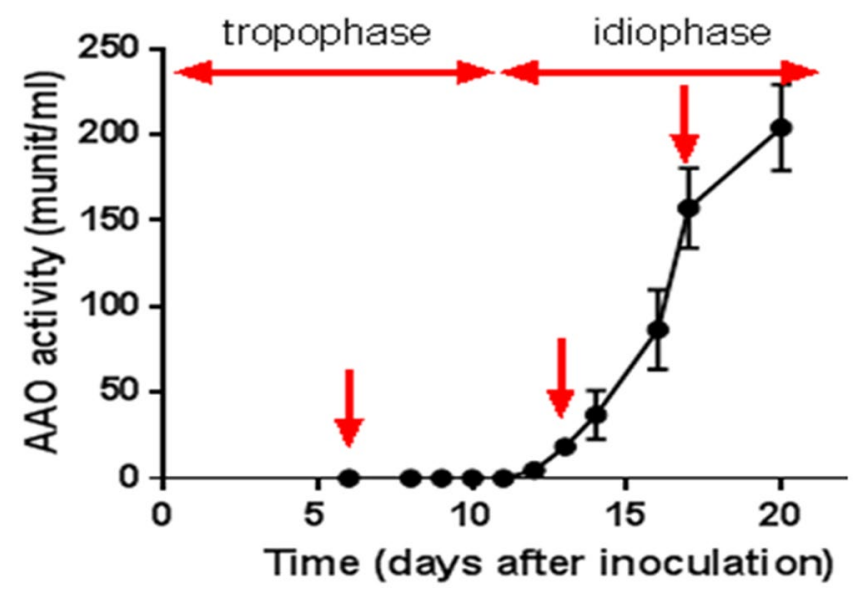

Figure 3. In vitro AAO activity at different growth stages of $P$. ostreatus. The activity of AAO was monitored in free cell extracts and was measured over 21 days. Arrows point to 6,13 and 18-day-old cultures that were further analyzed.

harbors a carboxin resistance cassette ${ }^{13}$ ], downstream of the constitutive $S d i 1$ promoter ${ }^{13,18}$. The resulting plasmid (pDF3) was used to transform P. ostreatus. Carboxin-resistant transformants were further analyzed, by PCR, to verify the presence of the insert. 

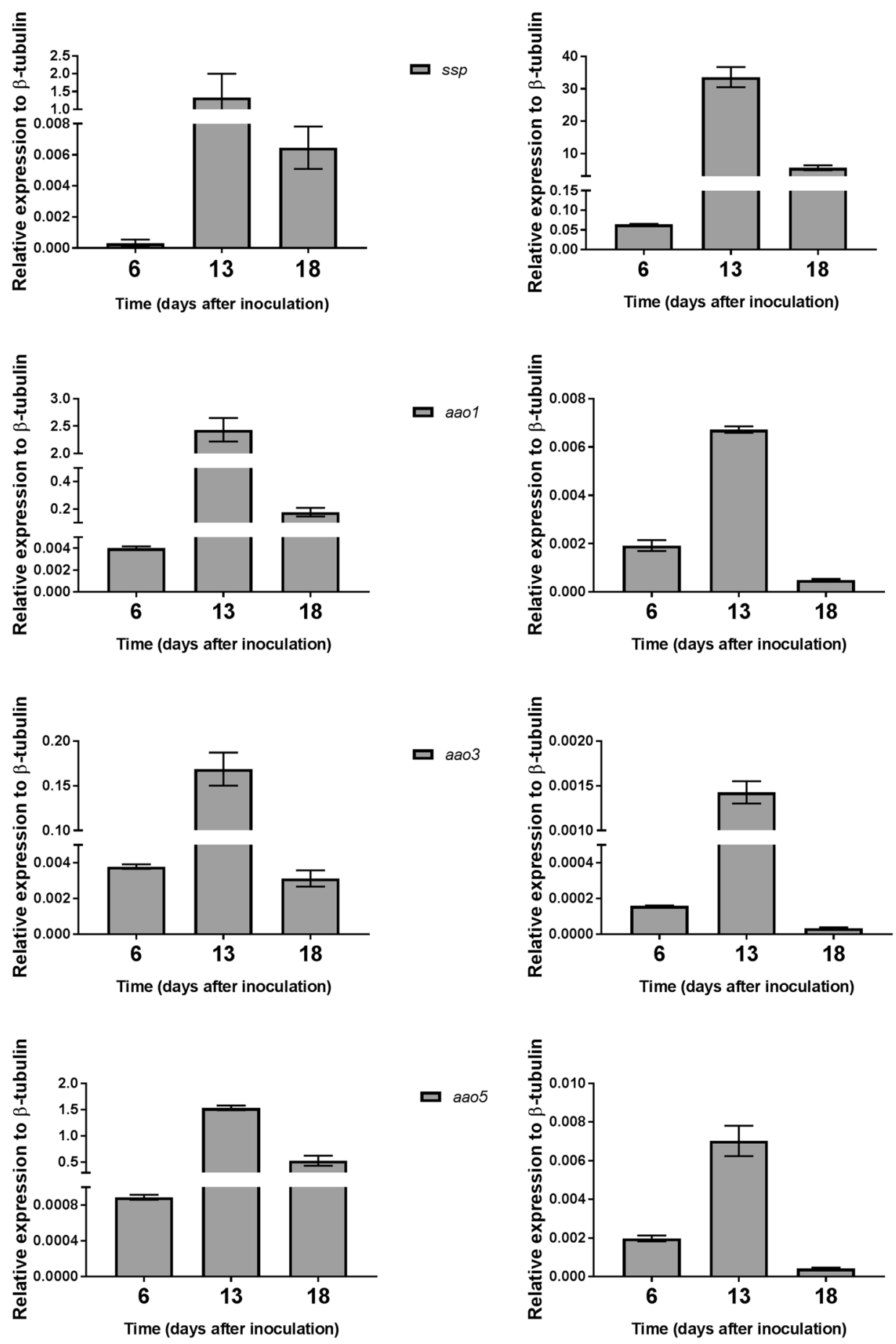

Figure 4. Gene expression of ssps, aaos and aad at different developmental stages. Expression levels relative to $\beta$-tubulin gene of ssps, aad 1 and aao1-6, measured at 6 (early growth stage), 13 (idiophase) and 18 (late idiophase) day-old cultures of $P$. ostreatus.

We analyzed the SSP-induction response of 5 transformants, 24 hours after exposure to HMF. The secreted proteins were resolved on an SDS-PAGE gradient gel, stained with Coomassie Blue, and the amount of SSPs examined. A clear reduction in SSPs was observed in transformants 3-6, 3-10 and 3-11, while transformant 3-36 and 3-38 exhibited SSP levels which were similar to the PC9 control strain (Fig. 6B). The differential expression of ssps was typical to RNAi transformants ${ }^{13,19}$. Based on these results we chose to focus our further analyses on transformants 3-6, 3-10 and 3-11.

We quantified the expression of ssps $24 \mathrm{hr}$ after exposure to HMF. The expression level was significantly decreased, by 4-110 fold, in the transformants, as compared to the PC9 control strain (Fig. 6A). When the wild 
A

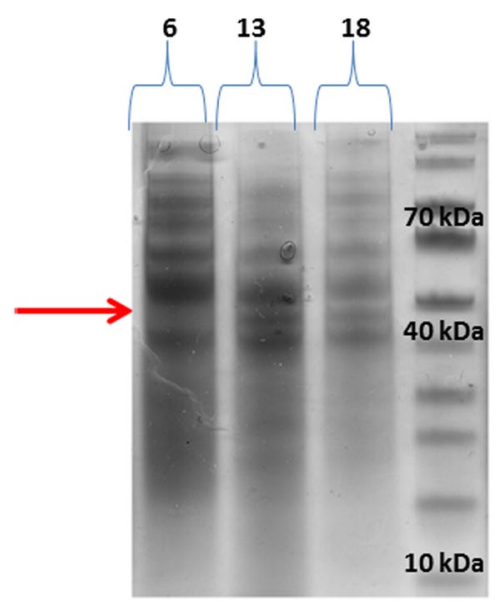

B

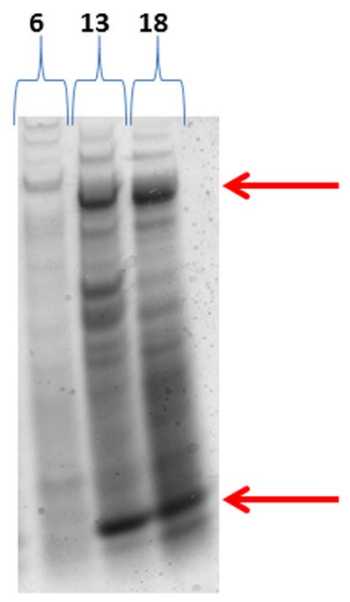

Figure 5. Profiles of secreted and cellular P. ostreatus proteins at different developmental stages. Cellular (A) and secreted (B) proteins were extracted from P. ostreatus at 6 (early growth stage), 13 (idiophase) and 18 (late idiophase) day-old cultures. Arrows point to AAD (A), AAO (B-up) and SSP (B-down). Protein identification was confirmed by MS analysis.

A

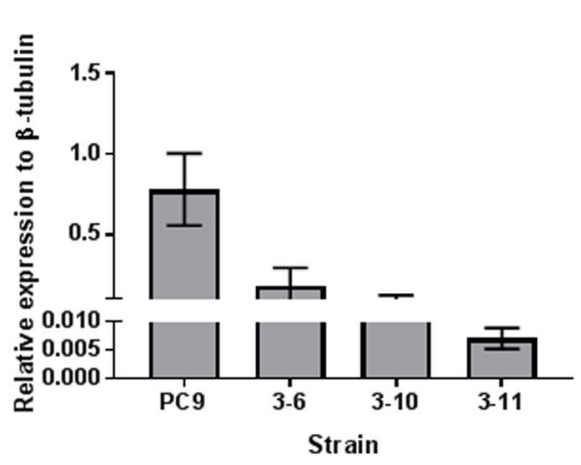

C

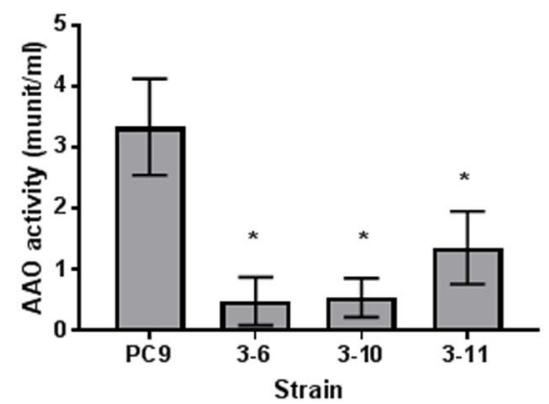

B

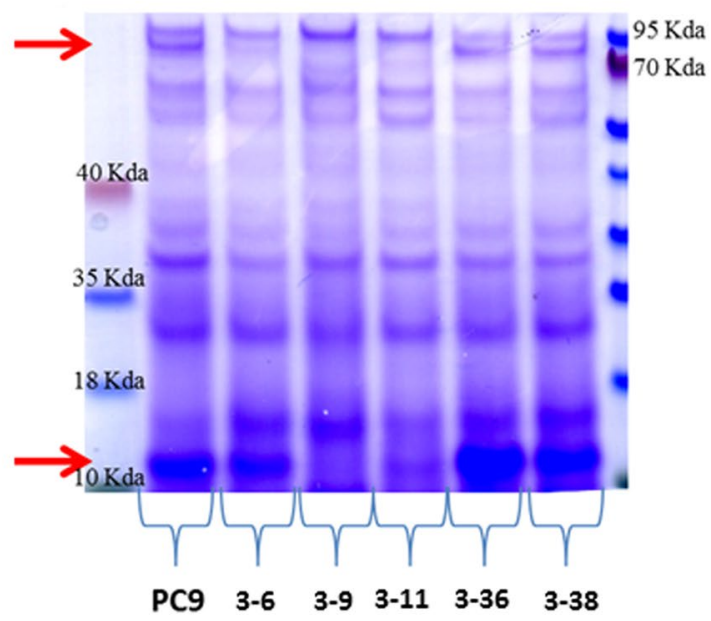

Figure 6. Reduced expression of ssps and AAO activity in a KDssp1 background, following HMF exposure. The expression and AAO activity of ssp1 knockdown transformants (3-8, 3-10 and 3-11) relative to the parental strain, PC9 was analyzed 24 hours after addition of $30 \mathrm{mM}$ of HMF. (A) Expression level of ssps relative to $\beta$-tubulin. (B) Profiles of secreted proteins. Arrows point to AAO (up) and SSP (down). (C) In vitro AAO activity in free cell extracts.

type fungus is grown in the absence of HMF the expression of ssps is negligible, the comparative decrease in expression levels of the transformants was difficult to quantitate.

The AAO accumulation was significantly reduced and barely detected in the RNAi transformants, relative to the PC9 strain (Fig. 6B). Furthermore, the levels of AAO activity seem to correlate with SSPs levels (Fig. 6C). The 

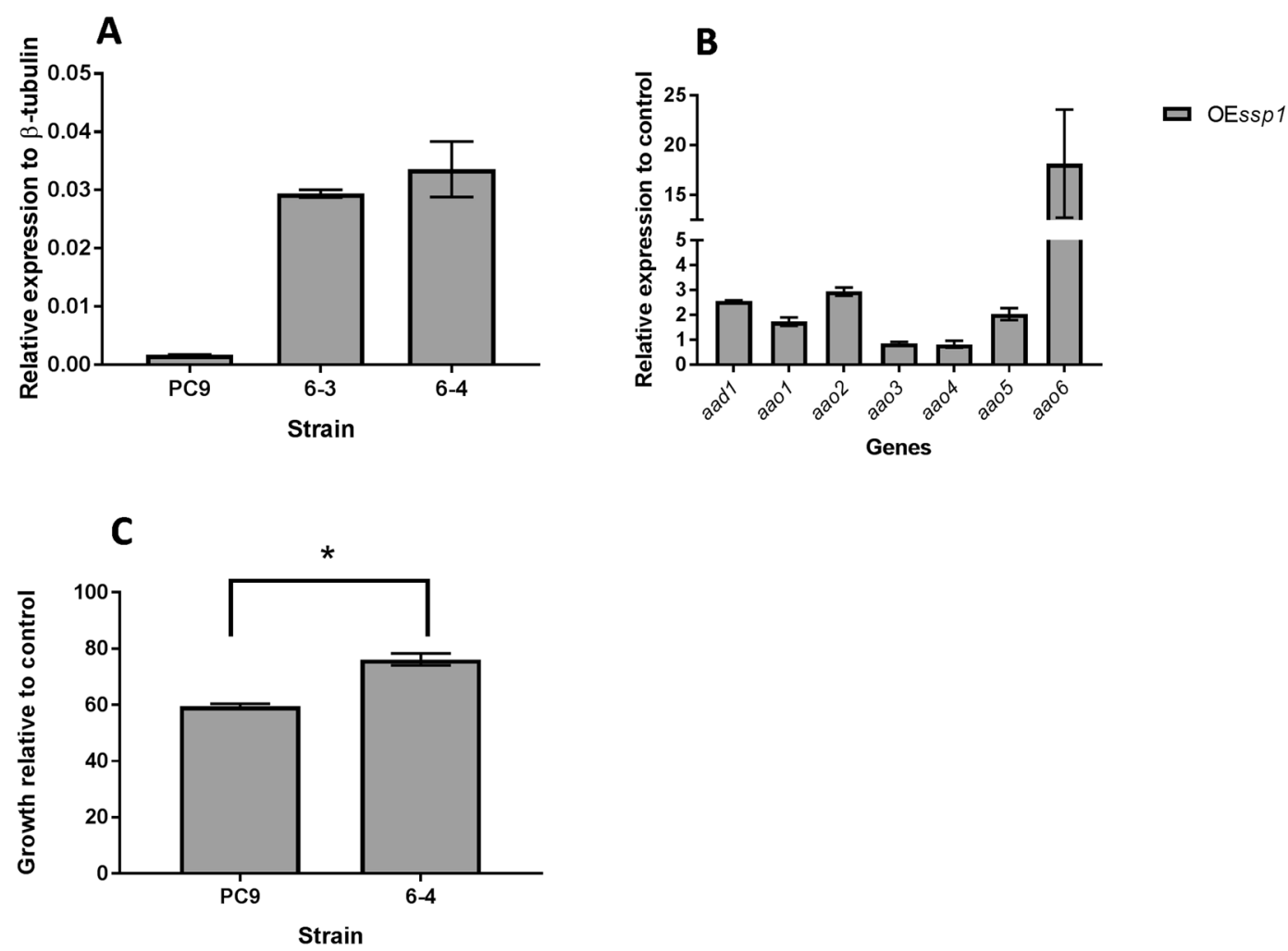

Figure 7. The over-expression of ssp1 results in elevated expression of aao1-6 and aad1 increased tolerance to HMF. The expression level of ssp1 in transformants bearing an $s s p 1$ over-expression construct $(\mathbf{A}, \mathbf{B})$ was analyzed in a 7-day-old culture. (A) ssps expression relative to $\beta$-tubulin. (B) Expression levels of aad 1 and aao1-6 in a 6-4 strain background, relative to the expression levels of these genes in the parental PC9 strain. (C) Relative colony growth of 8-day-old cultures of the parental PC9 strain compared to the ssp1 over-expression strain (6-4) after addition of $15 \mathrm{mM}$ HMF.

AAO activity level in the PC9 strain after exposure to HMF was $~ 3.5$ munit/ml, while the AAO activity of all the 3 transformants analyzed was significantly reduced by an average of $\sim 5$-fold, to $\sim 0.5-1.3 \mathrm{munit} / \mathrm{ml}$ (Fig. $6 \mathrm{C}$ ). To examine whether the reduction in AAO activity was a result of changes in transcription of the relevant genes, we quantified the expression of aao1-6, encoding for the six AAOs in the P. ostreatus genome. The expression of aao 4 and aao5 was reduced $\sim 2$-20-fold in all the 3 transformants. Transformants 3-6 and 3-11 also exhibited a $\sim 4$-fold reduction in aao1 and 3 expressions. The expression of the AAD coding gene aad 1 was also reduced $\sim 2$-fold in 3-6 and 3-10, and $\sim 5.5$-fold in 3-11. We decided to further characterize transformant 3-11, referred to as KDsp1, which did not exhibit phenotypic alterations except reduced growth rate of about $10 \%$ relative to parental strain.

Based on the results it seems that knockdown of ssp showed reduced expression of AAOs and AAD, after exposure to HMF.

Overexpression of SSP results in elevated expression of AAO and AAD. To determine what the consequences of over-expression of ssps, we produced a $P$. ostreatus strain the overexpressed ssp1. A plasmid containing the ssp 1 gene regulated by the $\beta$-tubulin promotor and terminator (pDF6) was transformed into $P$. ostreatus PC9, and the presence of the insert in resulting 4 transformants was verified by PCR. Preliminarily analysis was performed on transformants 6-3, 6-4 and 6-10 which exhibited significant elevation in ssps expression. Transformant 6-4 (designated OEssp1) was chosen for further analysis. This strain exhibited 20-fold elevated expression of $s s p$ (Fig. 7), and significantly increased SSP abundance at a 10 days culture, as measured by label free MS (data not shown). The strain exhibited small reduction of $\sim 10 \%$ in growth rate relative to PC9.

To examine whether the elevated expression of the ssps affected expression of AAO and AAD encoding genes, we quantified the expression of aao1-6 and aad 1 in the OEssp 1 strain in 7-day-old cultures, a time point corresponding to the fungal growth stage. The expression levels of aao2, aao5, aao6 and aad 1 were elevated $(\sim 3, \sim 2$, $\sim 18$ and 2.5-fold, respectively). However, the expression level of aao2 was not altered (Fig. 7). We concluded that the expression of at least part of the ligninolytic machinery was, indeed, affected by changes in SSP1 abundance. That and more, the OEssp1 was more tolerant toward HMF by 20\% (Fig. 7).

To analyze the physiological effects of the KDssp1 and OEssp1 strains, we monitored AAO activity along the different stages of fungal growth for 28 days. The OEssp1 strain exhibited measurable AAO activity (0.2 munit/ $\mathrm{ml})$ as early as 8 days in culture, 4 days before the PC9 parental strain $(0.033 \mathrm{munit} / \mathrm{ml})$. The AAO activity measured in the OEssp1 strain was elevated by $\sim 3-5$-fold relative to the PC9 strain during the idiophase, reaching 


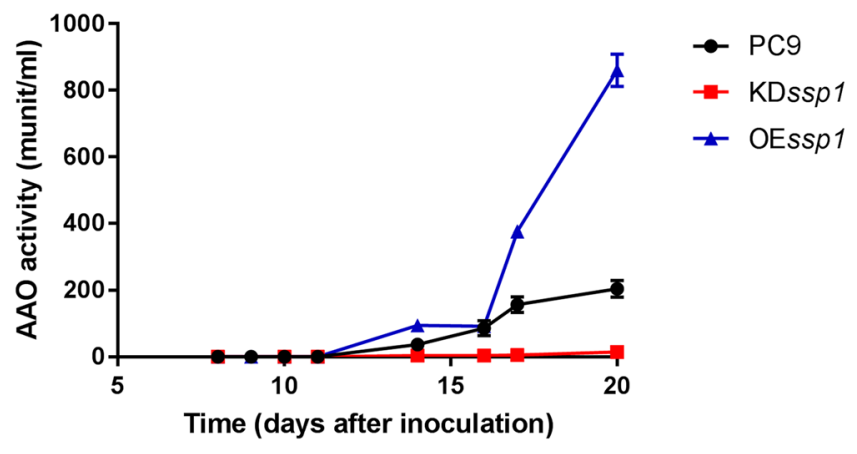

Figure 8. In vitro AAO activity is influenced in OEssp1 and KDssp1 strains. The extracellular activity of AAO was monitored in cell free extracts for 21 days in PC9, OEssp1 and KDssp1 strains.

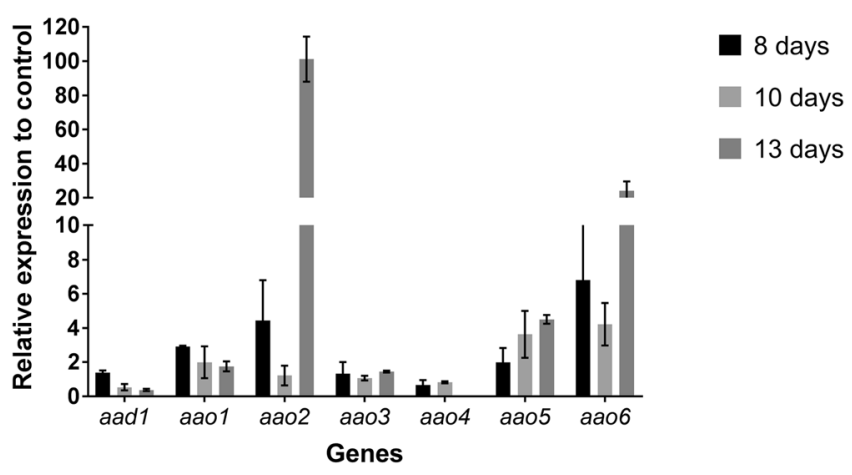

Figure 9. Elevated expression of aaos in a KDssp1 background at different growth stages. The expression levels of aad 1 and aao1-6 was determined relative to expression level of these genes in the PC9 and KDssp1 strains from 8,10 and 13-day-old cultures.

$\sim 700$ munit/ml and $\sim 200$ munit/ml, respectively in a 20-day-old culture. The opposite effect was observed in the KDssp1 strain; where the AAO activity was significantly reduced by $\sim 10-30$-fold, and reached only $\sim 14$ munit/ $\mathrm{ml}$ in a 20 day-old-culture (Fig. 8).

Surprisingly, in the KDssp1 strain, the reduced protein abundance and AAO activity levels did not correlate with transcription of the relevant genes [this was also evident in the second KDssp1 transformant (3-10)]. The expression levels of aao1, 2, 5 and 6 were elevated at 8, 10 and 13 days of culture relative to the PC9 strain (Fig. 9), suggesting non linearity between the translational and transcriptional response.

Changes in SSPs influence the abundance of versatile peroxidase 1 (VP1). To further examine the effect of the KDssp1 and OEssp1 strains on the secreted proteins over time, we analyzed the relative abundance of secretome at 8,10 and 13-day-old cultures. In the OEssp1 strain, the most striking effect was observed in the abundance of 40-50 KDa proteins, as early as in an 8-day-old culture (Fig. 10). The bands corresponding to this size range were excised from the SDS-PAGE gel and subsequently identified by MS as VP1, (versatile peroxidase 1), a predominant enzyme shown to be involved in lignin modification in $\mathrm{Mn}^{+2}$ - deficient media ${ }^{12,20}$. VP1 was identified in the secretome as a visible band in older (13 days) PC9 cultures, yet was almost undetectable in the KDssp1 strain (Fig. 10), suggesting the induction of VP1 expression in the OEssp1 strain, and the converse when SSP production was decreased.

We monitored the expression level of $v p 1$ in PC9, KDssp1 and OEssp1 at the corresponding time points. In the OEssp1, the expression of $v p 1$ was elevated in 8 and 10-day-old cultures (by $\sim 3.5$ - and $\sim 7$-fold relative to the PC9 strain, respectively), but without significant difference at day 13. Surprisingly, $v p 1$ transcript levels were also elevated in KDssp 1 by $~ 5$-fold after 8 days, but not 10 or 13 days, though the VP1 protein was not visible (on the basis of the Coomassie Blue - stained gel) in the secretome of that strain (Fig. 11).

\section{Discussion}

Understanding the functions of SSPs in fungi is still at its early stages, and considered the least characterized component of the secretome ${ }^{2,3}$. Nonetheless, a variety of possible functions for SSPs have been suggested, including the involvement in pathogenicity, symbiosis and degradative capabilities ${ }^{1,2,21-23}$. The production of SSPs is associated with lifestyles and ecological niches; biotrophs and symbionts usually have a higher proportion of species-specific SSPs than hemibiotrophs and necrotrophs ${ }^{3}$. SSPs have also been identified in saprophytic fungi and some of them resemble effector proteins of pathogenic fungi, suggesting alternative roles of SSPs ${ }^{3}$. Here, we present the analysis of a conserved, yet uncharacterized group of SSPs present in P. ostreatus, as well as other 


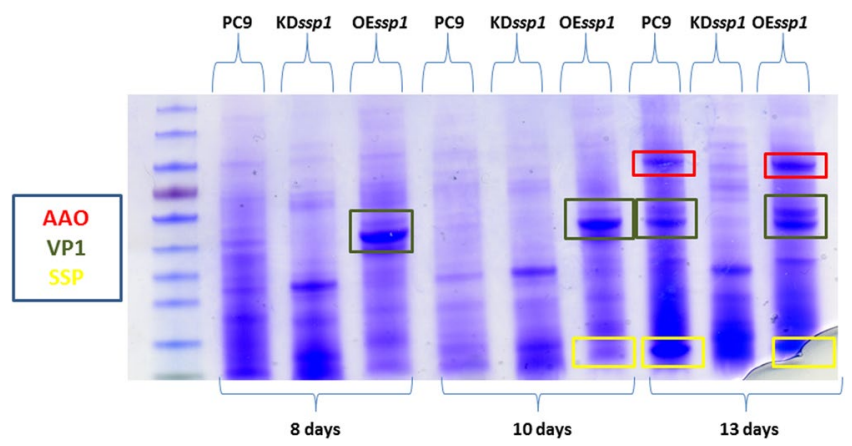

Figure 10. Profiles of secreted proteins at different growth stages in the OEssp1 and KDssp1 strains. SDS PAGE gel of secreted proteins from 8, 10 and 13-day-old cultures of the PC9, OEssp1 and KDssp1 strains. Significant differences are marked: AAO (red), VP1 (orange) and SSP (yellow), which were confirmed by MS analysis. The gel is representative to biological triplicates.

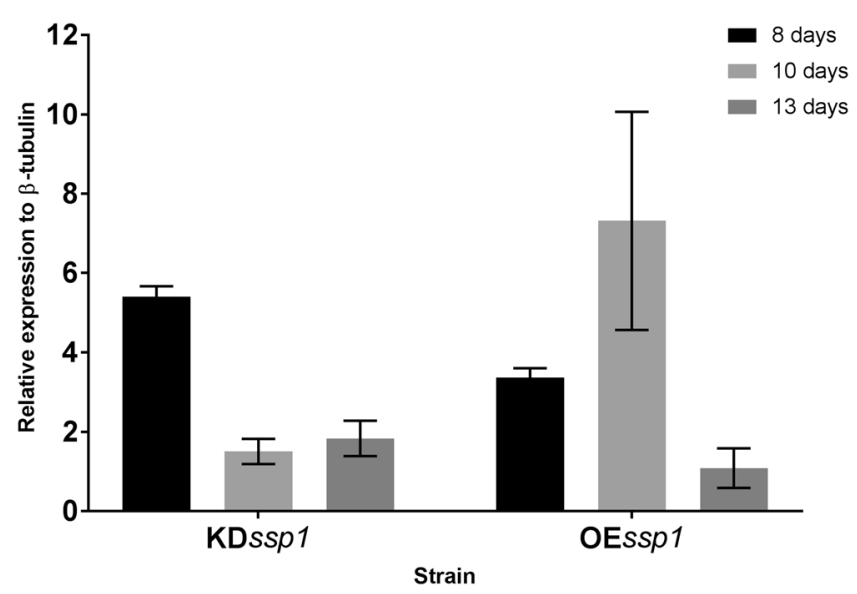

Figure 11. Expression of $v p 1$ influenced in OEssp1 and KDssp1 strains. The $v p 1$ expression levels in the KDssp1 and OEssp1 strains relative to $v p 1$ expression levels in the PC9 strain from 8, 10 and 13-day-old cultures.

basidiomycete. Most of the species are from the taxa Agaricomycotina such as Pleurotus eryngii and Coprinopsis cinerea, in which their function is also unknown. In a majority of the fungi there are multiple copies of the gene (2-12 genes) (Table S3), and a motif of secreted protein, similar to $P$. ostreatus. The P. ostreatus ssps were first identified as small secreted proteins, and the genes were upregulated to a level of up to 4500 -fold following exposure of the fungus to HMF (Fig. 1). Furthermore, their corresponding protein products were visibly elevated (on the basis of Coomassie Blue stained gels) in the fungal secretome following exposure to the furan (Fig. 1). These findings triggered our curiosity to further understand their potential function in the fungus.

It was suggested in Aspergillus sp, that SSPs may be involved in the fungal strategy to cope with toxicity of aromatic compounds or reactive oxygen species ${ }^{22}$. In the ligninolytic fungus, Phanerochaete chrysosporium, several genes coding for SSP were induced in the presence of toxic oak extracts ${ }^{24}$. Since the inhibitory compound, HMF is not present in the natural habitat of $P$. ostreatus, we hypothesized that other chemicals trigger a similar reaction. AAOs are responsible for detoxification of $\mathrm{HMF}$, and their activity is induced following exposure to the compound ${ }^{5}$. We therefore focused our efforts on other aryl-alcohols, known as inducers and substrates of AAOs as well as their prevalence as a functional group of the lignin molecule ${ }^{25}$. Indeed, aryl-alcohols strongly induced the expression of ssps, as well as the expression of aaos and aad (Fig. 2), thus suggesting a functional link between these three gene families. In culture media, in the absence of chemical exposure, SSPs, AAOs and AAD exhibited elevated expression only during the idiophase (Fig. 4). Activity of ligninolytic enzymes, considered as secondary metabolism, was previously shown during idiophase in P. chrysosporium ${ }^{26}$. Recently we have demonstrated that the ligninolytic enzyme-encoding mnp gene family as well as $v p$ s is also expressed during the same phase in P. ostreatus PC $9^{12}$. Genetic manipulation of ssp expression resulted in an effect on AAOs and AAD. The KDssp1 strain exhibited reduced expression of aaos and aad, after exposure to HMF (Fig. 6), and AAO activity during idiophase was almost abolished (Fig. 8). On the other hand, in the OEssp1 strain, elevated expression of aaos, aad and $v p 1$ was detected (Fig. 7), AAO activity was increased by 3-fold (Fig. 8), and tolerance toward HMF increased by $\sim 20 \%$ (Fig. 7). Based on the genetic and biochemical/physiological data presented, we propose that SSPs may function as regulators, at least in part, of the ligninolytic system. This is based on the evidence presented demonstrating the transcriptional, translational, and enzyme activity responses of several key ligninolytic system components (e.g., AAO, AAD and VP) following manipulation of ssp expression. 
We suggest that aryl-alcohol/HMF induce the production of SSPs, which are involved in the induced production of AAOs, AADs and VP that are responsible for the modification of lignin. In the presence of HMF, KDssp1 exhibit significant reduction in expression, as well as protein abundance of AAO and AAD (Fig. 6), suggesting SSPs may influence the transcription of those genes. Without the external addition of chemical inducers, regulation of SSPs is a bit different. The KDssp1 strain exhibited an unexpected phenomenon, in which aaos and $v p 1$ expression levels were elevated, yet the protein abundance of the ligninolytic enzymes was significantly reduced, and AAO activity is almost abolished. An explanation for this could be that the fungus transcribes an excess amount of transcripts of the relevant genes, but this abundance does not result in higher protein synthesis. Though surprising for a secreted protein, it may suggest the SSPs function at the protein level (either by preventing transcription or involved in degradation of proteins) and that the differences observed between transcript and protein abundance may be due to other regulating components at the transcriptional level that function as a feed-back to the reduction/lack of the enzymes.

We are intrigued how can SSPs, being secreted proteins without known catalytic or interacting domains, function as regulators of three large enzyme families. We explored the possibility that SSPs are part of a protein complex, which other members are important for regulation of transcription and translation. In Aspergillus sp, it was suggested that SSPs could directly interact with the enzymes to increase their activity ${ }^{22}$. Although utilizing different approaches (including co-immunoprecipitation and yeast 2-hybrid libraries for the screening of SSP-interacting proteins) did not yield conclusive results, our lack of success does not refute this hypothesis. The eventual success in finding SSP-interacting proteins may prove to be the key to delineate the pathway by which the observed SSP-based regulation occurs. Another possibility is that SSPs function by interacting with metabolites, and function as a "bridge" for signaling or interaction with other components. Possible metabolites may be the aryl-alcohols, which induce the production of SSPs (Fig. 2). For example, veratryl alcohol is a secondary metabolite, synthesized de-novo by several fungi (but not $P$. ostreatus) ${ }^{27}$, and shown to regulate the ligninolytic system by inducing the transcription of laccase ${ }^{28,29}$ and manganese peroxidases ${ }^{29}$.

Based on our findings, we suggest that SSPs and the generated OEssp1 mutant, which enhance the production of AAO, AAD and VP enzymes families, which can be potentially beneficial for various biotechnological applications. As the generated strain has increased tolerance towards HMF, the fungus can be used directly to degrade the toxic chemicals produced during biofuel pretreatment processes. It may also improve the rate of lignin degradation, which is necessary for biological pretreatment of biofuel lignocellulosic raw materials, or production of biomass utilized as ruminant feed ${ }^{30-32}$. To the best of our knowledge this is the first report suggesting regulators of the lignin degradation system, and a novel role of SSPs in saprophytic fungi.

\section{Methods}

Fungal growth and experimental conditions. P. ostreatus monokaryon strain PC9 (Spanish Type Culture Collection accession number CECT20311), which is a protoclone derived by de-dikaryotization of the commercial dikaryon strain N001 (Spanish Type Culture Collection accession number CECT20600) ${ }^{33}$, was used throughout this study. Strains KDssp1 and OEssp1, generated during this study (see below) were constructed in a PC9 background.

Fungal strains were grown and maintained in GP medium ( $2 \%$ glucose, $0.5 \%$ peptone (Difco, Franklin Lakes, NJ, USA), $0.2 \%$ yeast extract (Difco, Franklin Lakes, NJ, USA), $0.1 \% \mathrm{~K}_{2} \mathrm{HPO}_{4}$, and $0.05 \% \mathrm{MgSO}_{4} \cdot 7 \mathrm{H}_{2} \mathrm{O}$ ). When required, $1.5 \%$ agar was added. The gene and protein expression as well as activity assays were conducted in samples of fungal biomass or cell free extracellular extracts prepared from cultures that were maintained in stationary $100 \mathrm{ml}$ Erlenmeyer flasks containing $10 \mathrm{ml}$ of liquid media. The inoculum used for all experiments was one disk ( $5 \mathrm{~mm}$ diameter) of mycelium obtained from the edge of a young colony grown on solid medium and positioned at the center of the Petri dish or a flask. Cultures were incubated at $28^{\circ} \mathrm{C}$ in the dark.

Gene expression analyses. Total RNA was extracted from culture biomass, first ground under liquid nitrogen with mortar and pestle, then homogenized with QIA shredder spin columns (Qiagen, Hilden, Germany) and purified from the lysate using the RNeasy Plus Mini Kit (Qiagen, Hilden, Germany). cDNA was synthesized using the High Capacity cDNA Reverse Transcription Kit (Applied Biosystems, Carlsbad, CA, USA). Gene expression analyses were performed on an ABI StepOne Real-Time PCR Sequence Detection System and software (Applied Biosystems, Foster City, CA, USA), using Power SYBR Green PCR Master Mix (Applied Biosystems, Foster City, CA, USA). The PCR volume was $10 \mu \mathrm{l}$, using $20 \mathrm{ng}$ of total cDNA and $300 \mathrm{nM}$ oligonucleotide primers (Table S4). The thermal cycling conditions were as follows: an initial step at $95^{\circ} \mathrm{C}$ for $20 \mathrm{~s}$ and 40 cycles at $95^{\circ} \mathrm{C}$ for $5 \mathrm{~s}, 60^{\circ} \mathrm{C}$ for $30 \mathrm{~s}$, followed by a denaturation step to verify the absence of unspecific products or primer dimmers. To monitor the expression of ssps $50 \mathrm{nM}$ of primers were used and the thermal cycling was 40 cycles at $95^{\circ} \mathrm{C}$ for $5 \mathrm{~s}, 64^{\circ} \mathrm{C}$ for $60 \mathrm{~s}$. The $\beta$-tubulin (ID: 117235) gene was used as the endogenous control. The primer efficiency levels of the genes were with the range of $90 \%$ to $110 \%$. Amplification data were compared on the basis of the of $\Delta \mathrm{CT}$ method and presented as $2^{-\Delta \mathrm{CT}}$ or $\Delta \Delta \mathrm{CT}$ method and presented as $2^{-\Delta \Delta \mathrm{CT}}$. Data was normalized with respect to $\beta$-tubulin and calculated where $\Delta \mathrm{CT}=\mathrm{CT}$ target gene $-\mathrm{CT} \beta$-tubulin, and then $\Delta \Delta \mathrm{CT}=\Delta \mathrm{CT}$ treatment $-\Delta \mathrm{CT}$ control.

Protein expression profiles. For extracellular protein analyses, culture fluids were filtered through Whatman No. 1 filter paper followed by $0.45-\mu \mathrm{m}$ mixed cellulose ester filter paper (Whatman, Buckinghamshire, UK). The sample was then concentrated using a 10-kDa cutoff PM-10 membrane (Millipore, Amicon Division, Billerica, MA, USA) and treated with cOmplete (Roche Applied Science, Mannheim, Germany), after concentration. For intracellular protein extraction, mycelial samples were frozen in liquid nitrogen, pulverized, and suspended in lysis buffer (1 M sorbitol, 10 mM HEPES (pH 7.5), 5 mM EDTA, 5 mM EGTA, 5 mM NaF, $0.1 \mathrm{M} \mathrm{KCl,} \mathrm{0.2 \%} \mathrm{Triton} \mathrm{X-100,} \mathrm{cOm-}$ plete (Roche Applied Science, Mannheim, Germany) and homogenized. The homogenates were centrifuged for $40 \mathrm{~min}$ at $10,000 \times \mathrm{g}$ at $4^{\circ} \mathrm{C}$, and the supernatants were recovered and stored at $-70^{\circ} \mathrm{C}$ until analyzed. 
Protein concentration was determined using the BioRad protein assay kit (BioRad, Hercules, CA, USA). Proteins were separated on a NuPAGE $4 \%$ to $12 \%$ Bis-Tris gel in MES-SDS running buffer (Invitrogen, Grand Island, NY, USA) and visualized with Coomassie R-250 (0.125\%). The sample was subsequently analyzed by HPLC/mass spectrometry/mass spectrometry (LC-MS/MS) in an Orbitrap (Thermo Scientific, Waltham, MA, USA) mass spectrometer and identified by Sequest 3.31 software against the JGI genome database of $P$. ostreatus PC9 v1.0 (http://genome.jgi-psf.org/PleosPC9_1/PleosPC9_1.home.html) at The Smoler Proteomics Center of The Israel Institute of Technology (Technion).

Enzymatic activity assays. Aryl Alcohol oxidase (AAO) activity was assayed spectrophotometrically, as the oxidation of veratryl alcohol (3,4-dimethoxybenzyl) to veratraldehyde, monitored at $310 \mathrm{~nm}\left(\varepsilon_{310}=9,300 \mathrm{M}^{-1}\right.$ $\mathrm{cm}^{-1}$ ). The reaction mixtures contained $1 \mathrm{mM}$ veratryl alcohol in $50 \mathrm{mM}$ potassium phosphate, $\mathrm{pH}=6$. The assay was conducted in a volume of $200 \mu \mathrm{l}$ in microtiter plates at $30^{\circ} \mathrm{C}$, using the Synergy HTX Multi-Mode Microplate Reader (BioTek, Winooski, USA). An enzyme unit was defined as the amount enzyme producing $1 \mu \mathrm{mol}$ of product per minute.

Construction of KDssp1. The construct for RNAi silencing of ssp1 was designed with inverted 160-bp repeats, corresponding to $112-271$ bp of ssp 1 coding sequence, separated by a $213 \mathrm{bp}$ loop (linker region), under the control of sdil expression signals ${ }^{13}$. The construct was inserted into pCS22 (Genscript, Nanjing, China) using the NheI and AgeI restriction sites. The restriction sites were used to facilitate the introduction of the RNAi construct into pTMS $1^{13}$, harboring the carboxin resistance gene, $C b x^{\mathrm{R}}$, under the control of $s d i 1$ expression signals; the resulting plasmid was designated pDF3.

Construction of OEssp1. The ssp1 sequence was found in the JGI genome database of PC9 v1.0 (http:// genome.jgi-psf.org/PleosPC9_1/PleosPC9_1.home.html) as protein ID 65712. A restriction-free cloning technique $^{34,35}$ was used to replace the $v p 1$ (previously referred as $m n p 4$ ) with $s s p 1$ in pTMS12 ${ }^{36}$. The ssp1 gene was amplified from genomic DNA, using primers pTMS12-65712F and 65712-pTMS12R designed with www. rf-cloning.org ${ }^{37}$. The reaction was performed with Phusion ${ }^{\mathrm{TM}}$ High-Fidelity PCR Master Mix (Thermo Scientific, USA). Generating ssp 1 with promoter and terminator regions from $\beta$-tubulin with conjunct ssp 1 expressions and carboxin-resistance $\left(C b x^{\mathrm{R}}\right)$ cassette designated $\mathrm{pDF} 6$.

Fungal Transformation. Transformation was performed based on the PEG-CaCl $\mathrm{C}_{2}$ protocol previously adapted for $P$. ostreatus ${ }^{13,36}$. Carboxin was used as a selection marker, and resistance was conferred via introduction of the carboxin-resistance cassette $\left(C b x^{R}\right)$ in either pDF3 or pDF6. Competent protoplasts were produced by digestion of vegetative mycelium of $P$. ostreatus from YMG liquid culture with lytic enzymes. The lytic enzyme solution consisted of $2 \%$ (w/v) Lysing enzymes from Trichoderma harzianum (Sigma-Aldrich) and 0.05\% (w/v) Chitinase from T. viride (Sigma-Aldrich) in $0.5 \mathrm{M}$ sucrose as an osmotic stabilizer. The protoplasts were washed (by centrifugation at $450 \mathrm{~g}, 8 \mathrm{~min}, 4^{\circ} \mathrm{C}$ ) in STC solution $(18.2 \% \mathrm{w} / \mathrm{v}$ sorbitol, $50 \mathrm{mM}$ Tris- $\mathrm{HCl} \mathrm{pH} \mathrm{8.0,50} \mathrm{mM}$ $\mathrm{CaCl}_{2}, 0.5 \mathrm{M}$ sucrose). Then, $2 \mathrm{ml}$ protoplasts were mixed with $100 \mu \mathrm{l}$ transforming DNA ( $\left.300 \mathrm{ng} / \mu \mathrm{l}\right), 150 \mu \mathrm{l} \mathrm{hep-}$ arin solution (Sigma-Aldrich) ( $5 \mathrm{mg}$ dissolved in $1 \mathrm{ml} \mathrm{STC}$ solution), and $300 \mu \mathrm{l}$ single-strand $\lambda$ phage carrier DNA (Fermentas) $\left(500 \mu \mathrm{g} / \mathrm{ml}\right.$, after denaturation at $95^{\circ} \mathrm{C}$ for $5 \mathrm{~min}$ and immediate transfer to ice). After $40 \mathrm{~min}$ of incubation on ice, $10 \mathrm{ml}$ PTC solution (40\% w/v PEG\#4000, $50 \mathrm{mM}$ Tris- $\mathrm{HCl}$ pH 8.0, $50 \mathrm{mM} \mathrm{CaCl}_{2}, 0.5 \mathrm{M}$ sucrose) was added, and the mixture was incubated for $20 \mathrm{~min}$ at room temperature. The mixture was then plated on selective solid YMG regeneration medium, containing $0.5 \mathrm{M}$ sucrose and carboxin at a final concentration of $2 \mathrm{mg} / \mathrm{l}$. Transformants were isolated after $10-16$ days of incubation at $28^{\circ} \mathrm{C}$. Transformant stability was verified by three successive transfers to solid medium with carboxin selection $\operatorname{drug}(2 \mathrm{mg} / \mathrm{ml})$, after which the transformants were transferred to solid culture medium lacking the antibiotic.

cDNA libraries preparation and RNAseq. The mRNA from biological triplicates was isolated from $10 \mu \mathrm{g}$ total RNA samples using Dynabeads Oligo(dT)25 (Invitrogen) and fragmented by the RNA Fragmentation Reagents kit (Ambion). The mRNA fragments were precipitated with $0.1 \mathrm{vol}$ of $3 \mathrm{M}$ sodium acetate and 2 vol of cold $100 \%$ ethanol, and washed with $70 \%$ ethanol. The precipitate was resuspended in Tris-EDTA buffer. The first cDNA strand was prepared using the SuperScript III First Strand Synthesis kit (Invitrogen) and [d(N6)] random primers (Invitrogen), and the second cDNA strand was prepared using the Second strand buffer (Invitrogen), according to the manufacturer's instructions.

For the RNAseq experiments, the double-stranded cDNAs were end-labeled with different adaptors using the TruSeq DNA LT sample prep kit (Illumina), according to the manufacturer's instructions. The end-labeled cDNAs of about $200 \mathrm{bp}$ were purified by electrophoresis on a $2.5 \%$ low-melting point agarose gel (Qiagen, CA). The gel-purified cDNA libraries were amplified by PCR (TruSeq v2 LT sample prep kit PCR, Illumina), quantified, and checked for quality on an Agilent 2100 Bioanalyzer, and sequenced as single-end $50 \mathrm{bp}$ reads on an Illumina Genome Analyzer GX platform.

RNAseq data analysis. The sequence was mapped to the ORFs of the genome of P. ostreatus v1.0 (with Tophat v2.04 software ${ }^{38}$ and normalized expression determined for each gene as fragments per kilobase or exon model per million mapped fragments (FPKM) with the Cufflinks program v2.02 ${ }^{39}$. The statistical significance differences in FPKM were determined by the cuffdiff module of the cufflinks program with only $\log 2>1$ fold change in expression with adjusted P-values below 0.01 after false determination rate correction were considered significant. The protein coding sequences of PC $9 \mathrm{v} 1.0$ were annotated by a protein blastp search to the non-redundant protein database at the NCBI using Blast2GO v2. $8^{40}$ and e-value cutoff of 1e-5. Gene Ontology (GO) terms were used to assign biological annotation to each gene. Enrichment of GO terms for biological processes was by a Fisher's exact test with an adjusted P-value $<0.05$ as significant after a multiple testing correction. 


\section{References}

1. Alfaro, M., Oguiza, J. A., Ramirez, L. \& Pisabarro, A. G. Comparative analysis of secretomes in basidiomycete fungi. J. Proteomics 102, 28-43 (2014).

2. Pellegrin, C., Morin, E., Martin, F. M. \& Veneault-Fourrey, C. Comparative analysis of secretomes from ectomycorrhizal fungi with an emphasis on small-secreted proteins. Front. Microbiol 6, 1-15 (2015).

3. Kim, K.-T. et al. Kingdom-wide analysis of fungal small secreted proteins (SSPs) reveals their potential role in host association. Front. Plant Sci. 7, 186 (2016).

4. Saloheimo, M. et al. Swollenin, a Trichoderma reesei protein with sequence similarity to the plant expansins, exhibits disruption activity on cellulosic materials. Eur. J. Biochem 269, 4202-4211 (2002).

5. Feldman, D., Kowbel, D. J., Glass, N. L., Yarden, O. \& Hadar, Y. Detoxification of 5-hydroxymethylfurfural by the Pleurotus ostreatus lignolytic enzymes aryl alcohol oxidase and dehydrogenase. Biotechnol. Biofuels 8, 11 (2015).

6. Klinke, H. B., Thomsen, A. B. \& Ahring, B. K. Inhibition of ethanol-producing yeast and bacteria by degradation products produced during pre-treatment of biomass. Appl. Microbiol. Biotechnol. 66, 10-26 (2004).

7. Palmqvist, E. \& Hahn-Hagerdal, B. Fermentation of lignocellulosic hydrolysates. II: inhibitors and mechanisms of inhibition. Bioresour. Technol 74, 25-33 (2000).

8. Parawira, W. \& Tekere, M. Biotechnological strategies to overcome inhibitors in lignocellulose hydrolysates for ethanol production: review. Crit. Rev. Biotechnol. 31, 20-31 (2011).

9. Jönsson, L. J., Alriksson, B. \& Nilvebrant, N.-O. Bioconversion of lignocellulose: inhibitors and detoxification. Biotechnol. Biofuels 6, $16(2013)$

10. Kirk, T. K., Gifford, O., Drive, P. \& Farrell, R. L. Enzymatic 'combustion': the microbial degradation of lignin. Microbiology 465-505 https://doi.org/10.1146/annurev.mi.41.100187.002341 (1987).

11. Ruiz-Dueñas, F. J. \& Martínez, Á. T. Microbial degradation of lignin: How a bulky recalcitrant polymer is efficiently recycled in nature and how we can take advantage of this. Microb. Biotechnol. 2, 164-177 (2009)

12. Knop, D. et al. $\mathrm{Mn}^{2+}$-deficiency reveals a key role for the Pleurotus ostreatus versatile peroxidase (VP4) in oxidation of aromatic compounds. Appl. Microbiol. Biotechnol. 98, 6795-6804 (2014).

13. Salame, T. M., Yarden, O. \& Hadar, Y. Pleurotus ostreatus manganese-dependent peroxidase silencing impairs decolourization of Orange II. Microb. Biotechnol 3, 93-106 (2010).

14. Ruiz-Dueas, F. J., Fernndez, E., Martnez, M. J. \& Martnez, A. T. Pleurotus ostreatus heme peroxidases: An in silico analysis from the genome sequence to the enzyme molecular structure. Comptes Rendus - Biol 334, 795-805 (2011).

15. Grigoriev, I. V. et al. MycoCosm portal: Gearing up for 1000 fungal genomes. Nucleic Acids Res. 42, (2014).

16. Grigoriev, I. V. et al. Fueling the future with fungal genomics. Mycology 2, 192-209 (2011).

17. Demain, A. L. Regulation of secondary metabolism in fungi. Pure Appl. Chem 58, 219-226 (1986).

18. Honda, Y., Matsuyama, T., Irie, T., Watanabe, T. \& Kuwahara, M. Carboxin resistance transformation of the homobasidiomycete fungus Pleurotus ostreatus. Curr. Genet. 37, 209-212 (2000).

19. Ziv, C. \& Yarden, O. Gene silencing for functional analysis: assessing RNAi as a tool for manipulation of gene expression. Methods Mol. Biol 638, 77-100 (2010).

20. Salame, T. M. et al. Predominance of a versatile-peroxidase-encoding Gene, mnp4, as demonstrated by gene replacement via a gene targeting system for Pleurotus ostreatus. Appl. Environ. Microbiol. 78, 5341-5352 (2012).

21. Raffaello, T. \& Asiegbu, F. O. Small secreted proteins from the necrotrophic conifer pathogen Heterobasidion annosum s.l. (HaSSPs) induce cell death in Nicotiana benthamiana. Sci. Rep 7, 8000, https://doi.org/10.1038/s41598-017-08010-0. (2017).

22. Valette, N. et al. Secretion of small proteins is species-specific within Aspergillus sp. Microb. Biotechnol. https://doi.org/10.1111/17517915.12361 (2016).

23. Plett, J. M. et al. A secreted effector protein of laccaria bicolor is required for symbiosis development. Curr. Biol. 21, 1197-1203 (2011).

24. Thuillier, A. et al. Transcriptomic responses of Phanerochaete chrysosporium to oak acetonic extracts: Focus on a new glutathione transferase. Appl. Environ. Microbiol. 80, 6316-6327 (2014).

25. Hattori, T. \& Shimada, M. In Wood and Cellulosic Chemistry, Second Edition, Revised, and Expanded 547-571 (2001).

26. Kirk, T. K. \& Chang, H. M. Potential applications of bio-ligninolytic systems. Enzyme and Microbial Technology 3, 189-196 (1981).

27. de Jong, E., Field, J. A. \& de Bont, J. A. M. Aryl alcohols in the physiology of ligninolytic fungi. Microbiol. Rev 13, 153-188 (1994).

28. Mansur, M., Suárez, T. \& González, A. E. Differential gene expression in the laccase gene family from basidiomycete I-62 (CECT 20197). Appl. Environ. Microbiol. 64, 771-774 (1998).

29. Scheel, T., Höfer, M., Ludwig, S. \& Hölker, U. Differential expression of manganese peroxidase and laccase in white-rot fungi in the presence of manganese or aromatic compounds. Appl. Microbiol. Biotechnol. 54, 686-691 (2000).

30. Cohen, R., Persky, L. \& Hadar, Y. Biotechnological applications and potential of wood-degrading mushrooms of the genus. Pleurotus. Appl. Microbiol. Biotechnol. 58, 582-594 (2002).

31. Singh, A. P. \& Singh, T. Biotechnological applications of wood-rotting fungi: A review. Biomass and Bioenergy 62, 198-206 (2014).

32. Knop, D., Yarden, O. \& Hadar, Y. The ligninolytic peroxidases in the genus Pleurotus: divergence in activities, expression, and potential applications. Appl. Microbiol. Biotechnol. 99, 1025-1038 (2014).

33. Larraya, L. M. et al. Molecular karyotype of the white rot fungus Pleurotus ostreatus. Appl. Environ. Microbiol. 65, 3413-3417 (1999).

34. Bryksin, A. V. \& Matsumura, I. Overlap extension PCR cloning: a simple and reliable way to create recombinant plasmids. Biotechniques 48, 463-465 (2010).

35. Unger, T., Jacobovitch, Y., Dantes, A., Bernheim, R. \& Peleg, Y. Applications of the Restriction Free (RF) cloning procedure for molecular manipulations and protein expression. J. Struct. Biol. 172, 34-44 (2010).

36. Salame, T. M. et al. Release of Pleurotus ostreatus versatile-peroxidase from $\mathrm{Mn} 2+$ repression Enhances anthropogenic and natural substrate degradation. PLoS One 7, (2012).

37. Bond, S. R. \& Naus, C. C. RF-Cloning.org: an online tool for the design of restriction-free cloning projects. Nucleic Acids Res. 40, W209-W213 (2012).

38. Trapnell, C., Pachter, L. \& Salzberg, S. L. TopHat: Discovering splice junctions with RNA-Seq. Bioinformatics 25, 1105-1111 (2009).

39. Trapnell, C. et al. Transcript assembly and quantification by RNA-Seq reveals unannotated transcripts and isoform switching during cell differentiation. Nat. Biotechnol. 28, 511-5 (2010).

40. Conesa, A. \& Götz, S. Blast2GO: A comprehensive suite for functional analysis in plant genomics. Int. J. Plant Genomics 2008, (2008).

\section{Acknowledgements}

This study was supported by grant from the Israel Science Foundation (ISF). Daria Feldman was supported by a fellowship from the President of Israel fund granted by the Estates Committee. 


\section{Author Contributions}

D.F. and D.J.K. carried out the experimental studies and drafted the manuscript. Y.H., O.Y., and N.L.G. conceived the study, and participated in its design and coordination, and helped to draft the manuscript. All authors read and reviewed the manuscript.

\section{Additional Information}

Supplementary information accompanies this paper at https://doi.org/10.1038/s41598-017-15112-2.

Competing Interests: The authors declare that they have no competing interests.

Publisher's note: Springer Nature remains neutral with regard to jurisdictional claims in published maps and institutional affiliations.

(c) (i) Open Access This article is licensed under a Creative Commons Attribution 4.0 International License, which permits use, sharing, adaptation, distribution and reproduction in any medium or format, as long as you give appropriate credit to the original author(s) and the source, provide a link to the Creative Commons license, and indicate if changes were made. The images or other third party material in this article are included in the article's Creative Commons license, unless indicated otherwise in a credit line to the material. If material is not included in the article's Creative Commons license and your intended use is not permitted by statutory regulation or exceeds the permitted use, you will need to obtain permission directly from the copyright holder. To view a copy of this license, visit http://creativecommons.org/licenses/by/4.0/.

(C) The Author(s) 2017 